\title{
Cultivating Diverse Online Classrooms Through Effective Instructional Design
}

Karen L. Milheim

Walden University, USA 
Published in the United States of America by

IGI Global

Information Science Reference (an imprint of IGI Global)

701 E. Chocolate Avenue

Hershey PA, USA 17033

Tel: $717-533-8845$

Fax: 717-533-8661

E-mail: cust@igi-global.com

Web site: http://www.igi-global.com

Copyright ( $\odot 2018$ by IGI Global. All rights reserved. No part of this publication may be reproduced, stored or distributed in any form or by any means, electronic or mechanical, including photocopying, without written permission from the publisher.

Product or company names used in this set are for identification purposes only. Inclusion of the names of the products or companies does not indicate a claim of ownership by IGI Global of the trademark or registered trademark.

\section{Library of Congress Cataloging-in-Publication Data}

Names: Milheim, Karen L., 1974- editor.

Title: Cultivating diverse online classrooms through effective instructional design / Karen L. Milheim, editor.

Description: Hershey, Pennsylvania : Information Science Reference (an imprint of IGI Global), [2018]

Identifiers: LCCN 2017015191| ISBN 9781522531203 (Hardcover) | ISBN 9781522531210 (eBook)

Subjects: LCSH: Multicultural education--Computer-assisted instruction. I

Instructional systems--Design. I Culturally relevant pedagogy.

Classification: LCC LC1099 .C749 2018 I DDC 370.117--dc23 LC record available at https://lccn. loc.gov/2017015191

This book is published in the IGI Global book series Advances in Educational Technologies and Instructional Design (AETID) (ISSN: 2326-8905; eISSN: 2326-8913)

British Cataloguing in Publication Data

A Cataloguing in Publication record for this book is available from the British Library.

All work contributed to this book is new, previously-unpublished material.

The views expressed in this book are those of the authors, but not necessarily of the publisher.

For electronic access to this publication, please contact: eresources@igi-global.com. 


\title{
Chapter 12 \\ Modelling for Value \\ Systems in a Diverse Online Program in the Caribbean
}

\author{
Camille Dickson-Deane \\ University of Melbourne, Australia \\ LeRoy Hill \\ Anguilla Community College, Anguilla \\ Laura E. Gray \\ University of the West Indies Open Campus, USA
}

\section{ABSTRACT}

The authors present a conceptual framework to guide the participation of students in an online instructional design program. The online program has socio-cultural influencing factors that confound the already diverse nature of the offering. The framework intends to encourage a value system for students that can be used to guide their knowledge and performance as they pursue the tenets of the field of instructional design. Elmore's mode of leadership, Bourdieu's theory of habitus and Hofstede's cultural dimensions theory are used to create a foundation for the framework whilst acknowledging the complexities of the diverse environment. The framework supports and acknowledges the knowledge expected of novice instructional designers through the use of guides whilst acknowledging the systemic and systematic individualistic change processes that will occur. 


\section{INTRODUCTION}

Instructional design is a relatively new field, with its historical roots drawing from a number of other fields which include cognitive science and behavioral psychology (Reiser, 2001, 2001). This field, has expanded with the onset of the use of the technology in educational practices, and then furthermore with the eLearning movement (Kidd, 2009). As eLearning and online learning became somewhat of a founding principle for which instructional design could be guided, the research in the field also expanded to accommodate factors that were not typically present in traditional instruction (Moore \& Kearsley, 2011; Reiser, 2001). One factor that provides an ongoing discussion is the differences that contribute to the uniqueness of each available online learning context is culture. This factor allows for online learning experiences that are derived from belief systems in an effort to create what is subjectively deemed a successful learning outcome. The subjectivity of the value of the product is important, not only to those who offer the online learning experience, but most importantly to those who are the recipients of such outcomes.

\section{Interpreting Value and Culture [Together]}

The word value as a verb describes worth or importance to which the descriptor is assigned. As a noun, value provides a standard or an associated behaviour or judgement. As both definitions apply to the online learning environment, the learner is seen as a key recipient and evaluator of the experience. The experience in an online learning environment speaks to a specific design that incorporates [tangible] artefacts, interactions towards functionality and knowledge, and tools that manage the relationship between the artefacts and the interactions. The online learning design space is, and can be, a complex area, especially as it is still being measured for reliability and validity in delivery (Clark, 1983; Collins, 2000; Noble, 1998; Squires \& Preece, 1996). The design of the environment, like any other learning space, will be the foundation of nuanced efforts as they address the appropriateness of the delivery as per the learners and instructors point of view. These efforts are informed and confounded by belief systems, prior experiences, abilities to access technologies, current knowledge, technological infrastructure, overt skills, and many other factors. Understanding how these factors contribute to the delivery of an online course in a program is pertinent as the tenure provided for each course, can allow for the misconception that the experience is short-lived. This misconception drives the belief that these factors are not truly reflective of the elements of some cultural systems.

Online courses are initiated for a specific time, during which, the design of the course which sits on a technological infrastructure becomes alive - with varying 
actors. The actors, in this case, learners and instructors, each bring different ways of thinking, preferences in technology use, and even indoctrinated perceptions of what and how education should be delivered. These factors, when deconstructed for each instance of an online course, create a cultural ecosystem which must move beyond the physicalities of the environment towards the determined pedagogical aspects for the course. The value system that is introduced during this short period is drawn from previous individual experiences, associative discussions (sometimes called gossip), feelings, general understandings and more, all of which must become tangible displayed in the design to the learners and instructor. The contextual nature of this system draws on the individual dispositions, the group dynamics, the social context in which the system is situated, and the technology [tool] used to create the system. This combination contributes to a value system which draws on the behaviours, ways of thinking, perceptions, and reactions - all towards general decision making for each contributor (Bourdieu, 2011; Harvard X, 2017; Hofstede, 2001). Understanding the process of valuing the experience towards the intent of learning in an online course and acknowledging that the online course has a specific value, which is interpreted by those participating in the course, will introduce qualities and dimensions to the online course design and vice versa. Most online course design introduce a network of interactive factors that can address the intersection of nationalistic beliefs and individual cultural and social currencies towards an environment of learning that is governed by pre-existing belief systems (Bourdieu, 2011; Hofstede, 2001). These factors are the fuel that drives this type of course and should be observed and cultivated towards achieving the goal.

\section{Cultural and Nationalistic Beliefs}

Back in the late 1960's and early 1970's, when IBM was in its infancy, Geert Hofstede developed his Theory of Cultural Dimensions. The original theory proposed four dimensions where one could analyze cultural, and eventually, nationalistic, values: masculinity/femininity, individualism/collectivism, power distance, and uncertainty avoidance (Hofstede, 2001). These dimensions were applied, at the time, to the culture of workplaces, but over the years, were also applied to both large and small national cultures. Later, two more dimensions were added: indulgence/restraint and long-term orientation/short-term orientation (see Figure 1). Each of these indexes can provide a different lens through which education is seen and used (Henderson, 2007; Parrish \& Linder-VanBerschot, 2010). The six indexes all play their own role in segmenting characteristics which can be used to identify a person from a particular society/country and furthermore and individual within their own sociocultural environment. 
As a learner enters an online course, their dominant characteristics are used to guide them through the online learning environment. What can be challenging is understanding that the design of the online course is guided by the Instructor/ designer and in some aspects the administrator's dominant characteristics - some of which may not be similar to the student (Henderson, 2007; Moore, Dickson-Deane, \& Liu, 2014; Parrish \& Linder-VanBerschot, 2010). Being aware of sensitivities and what is appropriate based on a student's dominant characteristics is a difficult task in the online learning realm. This becomes an even more trying task when the decisions being made in the design of the infrastructure that supports environment do not accommodate or even acknowledge that there will be participants who will have different use and access needs/privileges. Whilst understanding the factors that affect the general use and access of the course, there must be further consideration to what is required as part of the learning objectives within the course (Thomas, Mitchell, \& Joseph, 2002).

Instructional design is a field which requires a general understanding of how education should be delivered thus drawing on a variety of other fields (i.e., graphic design, computer science, cognitive psychology, interaction design, etc..). The principles which are used to deliver the content (which are foundationally instructional design) using online instructional design principles without consideration for the learners socio-cultural characteristics and context is the challenge. Thus, there can be hindrances when an instructor's expectations in a course do not match a learner's effort. The hindrances can grow exponentially because of nature of online and then understanding that the mental models of the learner and the instructor (for basic

Figure 1. Hofstede's (2001) cultural dimensions

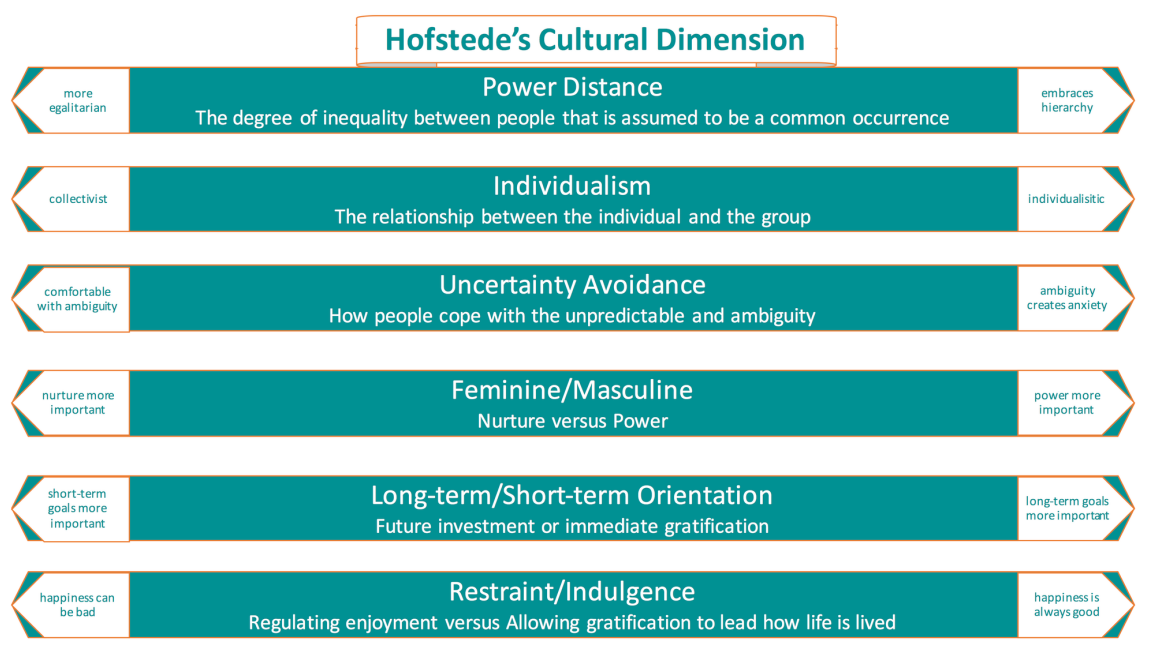


activities) differ. Lack of accommodation and mostly awareness affects learners in online settings as their own understanding of basic foundational needs may not be as pervasively known (Thomas et al., 2002) or in some instances considered.

\section{Individual Cultural and Social Currencies}

In an online learning environment, learners access material and contribute to the learning community based on the course requirement. These activities are typically guided by who else is in the course, the [online] relationships they have developed, and their decided level of participation. As technology is used to communicate and disseminate the content with which the learning occurs, their decisions on when, how much, and what forms of communications they use, also add to the climate of the learning environment. The climate can enhance or hinder the autonomy of an individual learner, thus influencing the value placed on the learning environment. This is specifically important when collaborative activities call for co-creation, evaluation, transference and repurposing of information and knowledge (Costa, 2013). These activities are guided by the dimensions outlined in Hofstede's (2001) research, thus influencing each individuals social and cultural currencies as he or she interacts in the learning environment. The varying factors that contribute to the individualistic nature of each learner add to the personal yet negotiated connections formed in the environment. The decisions made with the connections and values placed on the outcomes are what influences how and what is learned to make the course a success or failure (see Figure 2) (Bourdieu, 2011; Czerniewicz \& Brown, 2013, 2014). These values are further influenced by the past, current experiences, and the values attached to each experience, be it associated with family, friends, or society at large (Beckman, Bennett, \& Lockyer, 2014). All of this serves to create a new system through which each learner will operate in the environment.

\section{Leading Learning Online}

Part of disseminating knowledge in the field of instructional design, is creating a learning community where sharing and collaborations thrive in an effort to build new ways and new solutions. This means that the instructor's role in delivering an online instructional design course is to lead the students using the same methods that are expected to be used in practice. Leading learning online, is an expected behaviour from an online instructor. This expectation includes the assumption that the demonstrated behaviour, although mediated by technology will seamlessly be understood and embraced by the student. What really occurs is that the student observes the behaviour, tries to match the behaviour to their own belief systems and then, in an attempt to translate toward the expectation, provides some evidence 
Figure 2. Illustration of an individual drawing from their environment to create their habitus

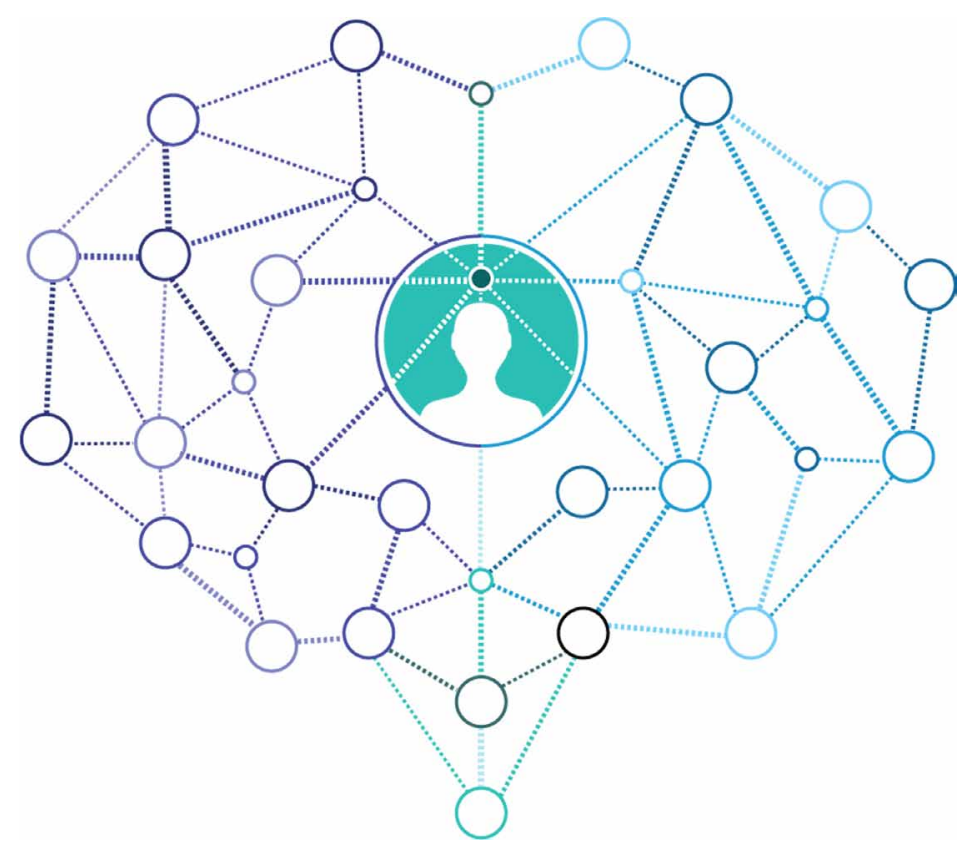

(by duplication). This can work if the instructor's socio-cultural norms match the students - but what happens when there is a disconnect? Elmore's Modes of Leadership illustrate the behaviours that help build specific types of relationships based on uniquely-characterised demonstrations (see Figure 3). This means that a student can be from a hierarchical individual environment and understand some of the distributed individualised instructor behaviours and still adhere to their own mode of learning - even it is to their detriment. Leading learning in an online context requires more care as the methods used to lead and create leaders may conflict and be distorted through the access and use of technologies

\section{The Context}

The Caribbean is a group of approximately 700 islands strategically located in the area east of Central America, between the North and South American mainland and is often characterized as a socio-cultural "melting pot." Such designation is primarily due to its varied, complex, historical and cultural beginnings. Conversely, the historical and cultural context is overshadowed by capitalist exploitation and conquest (Beckles, 1993; Williams, 1970). The exploitation of the abundant physical 
Figure 3. Elmore's (2016) modes of learning

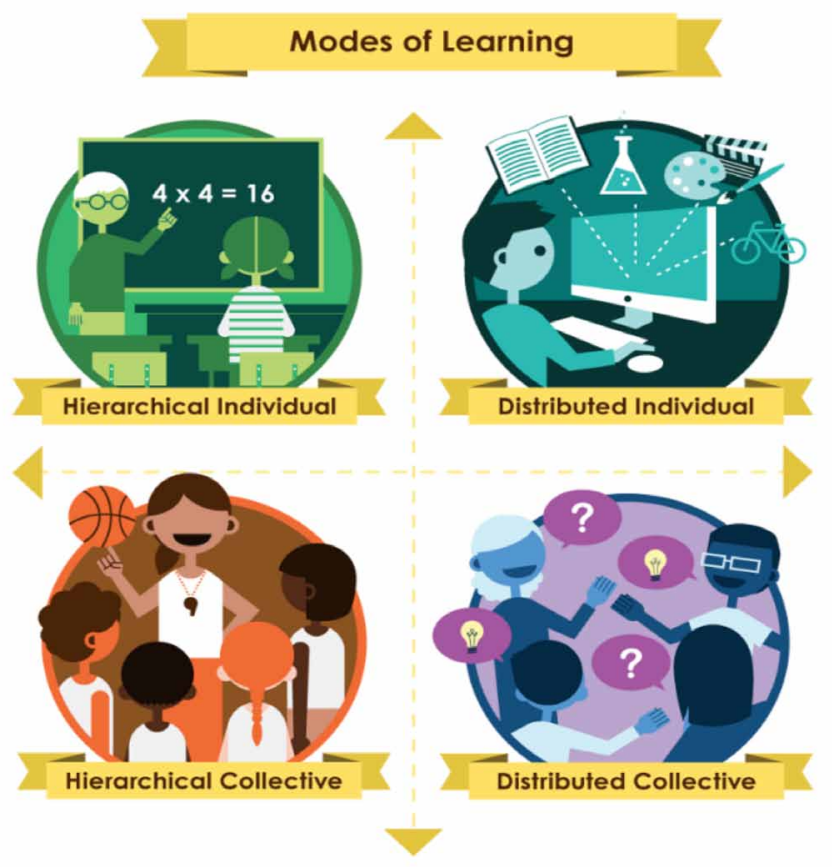

and natural resources by the diverse peoples who came, gave way to the presentday complexity of the socio-cultural landscape. In this way, the convergence of the diverse people in a limited locality provides a Caribbean environment with its distinctive, intermix of various language, political, religious systems (V. Rubin, 1960). Consequently, the people within this region speak a variety of languages including English, Spanish, French and Dutch, with many islands exhibiting a creolized language or patois that is distinctive from territory to territory. This Caribbean socio-cultural environment is compounded by the socio-cultural contribution made by indigenous pre-Columbian civilizations that predated the arrival of the Europeans, Africans, East Indians and Chinese. The diversity in the Caribbean is seen from each island or territory - specifically and explicitly in the spoken language and people, but also through the general belief systems, socio-political structures and telecommunications infrastructures. These differences guide how any one island's population communicates, as the telecommunications infrastructure varies from island to island (Dickson-Deane \& Deane, 2013). Each island has its own telecommunication providers, and some providers have presence throughout several countries - variations of monopolies of products and services. This thus influences how present-day communication and distance learning occurs in this region, whereby communication is unique to how it is used for information and knowledge sharing. 
The influence of socio-cultural perspectives on how communication technologies are used and accessed is not always clear to those who use and access them. The communication technologies and channels create networks of access capabilities and their design and implementation can sometimes be forged by others. The historical nature of industries in locations where the application methodologies are borrowed or copied affects and contributes to the cultural makeup. This thus forms a pattern of adopting solutions and methods that do not quite suit the culture and thus shifts how individuals think, interact and be.

\section{THE ONLINE LEARNING CONTEXT IN THE CARIBBEAN}

Traditionally, education in the Caribbean is didactic and paternalistic in its design and offering (Carrington, 1993; Knight, 1990; Rubin, 1957). This is mostly linked to the history of how education was developed in the region and then through each island's cultural roots. Even though the region's historical foundations for education systems has similarities, there is an underlying desire for change. Many of the individual governments want educational reform that is systematic and systemic (B. Robinson $\&$ Latchem, 2002). This is to provide education that truly addresses the needs of the population by reviewing the core principles of instruction and curriculum. Instruction is typically seen as a public service to the population, as opposed to being for profit and/or for individualistic gain. This belief system, although consistently displayed through the many countries in the region, may have small variances which make for an interesting makeup of different education systems.

The Caribbean Community (CARICOM) has a regional university that offers education to those who are citizens within the region, thus providing a customized educational solution. This educational initiative was established approximately 70 years ago to serve primarily the English-speaking countries in the region. There are four main campuses, three of which are based on islands, with the fourth guiding the distance learning activities for the university. The creation of the fourth campus specifically addressed the need for CARICOM nationals so that they were no longer required to physically attend a campus in order to acquire a post-secondary level of education. This campus uses the distance education model to provide online courses, certificates, and degrees to the community at large. This design also provides a great opportunity for more nationals to be educated, with the hope of increasing and redistributing the skill sets on different islands. 


\section{ISSUES, CONTROVERSIES, PROBLEMS: INSTRUCTIONAL DESIGN CHALLENGES}

As this fourth campus addresses a need of the community, the Master's in Instructional Design program also fulfills a dearth of knowledge and skill that is beneficial to the design of educational offerings in the region. The field of instructional design is not widely known in the Caribbean, and thus many sectors, both business and educational alike, do not understand the purpose of the field. This also creates a bit of a challenge, as instructional design is a relatively new field that has some of its foundational knowledge in education, and attributing how education is designed to these foundations can be difficult if there is a lack of awareness. The students of the master's program include primary and secondary educators, trainers and military personnel. There are also some who are pursuing the program to transition to the field and/or to diversify their own knowledge. Thus, the newness of the program offering is also challenged by the field and finding its place in Caribbean societies.

\section{Describing the Master's Program Environment}

The course environment, while relatively familiar to other English-speaking nations such as Great Britain, the United States, and Australia, is one that is rather new to those pursuing the master's degree in instructional design. For example, in these courses, students are expected to approach their learning from a constructivist approach rather than a carefully teacher-led behavioral (and thus, paternalistic) approach. Students are required to complete, and pass, three components which typically consist of between three and four individual assignments, a group assignment, and participation in weekly class discussions related to the course readings/topic.

This design is quite different in several ways from what is typical within the region. For example, a group assignment, which is usually due at the end of the course and is required in lieu of a written, proctored final exam, requires that students form collaborative groups during the first or second week of each semester, and, as such, students will work on this project throughout the entirety of the semester. These projects are worth between 30 and 40 percent of each student's final grade in the course. This high premium placed on group work and group collaboration is indicative of the importance of instructional designers being able to collaborate and work together on various design projects within the workplace (Spector et al., 2006). However, many students in the Caribbean are simply not accustomed to working this way; instead, they come into the program expecting to be told what to do and when to do it by the facilitator as well as focus on their own individual knowledge. 
In this instance, the facilitator draws on their own expectations for performance from a variety of experiences. The typical facilitator may not currently live in the Caribbean although she did at least her primary and secondary schooling in the region. She has a terminal degree in instructional design or a related field and has taught online for at least ten years. She has a good understanding of education in the other countries (e.g., United States and Great Britain) and has contributed scholarly directly and indirectly to the field of instructional design. Whilst the core value system of the facilitator has origins similar to that of the students, there are variations and manipulations which incorporate the experiences external to the Caribbean. The value system demonstrated by the facilitator creates a new source for a paradigm shift which is illustrated through the course design.

The facilitator's value system introduces another aspect of the course setup to which the students are often not accustomed - the ability to problem-solve and think "outside the box." Because education in the region is such that students are used to just memorizing and regurgitating information, many students enter the course environment ill-prepared to create and solve problems. This expectation which is seen as low-order thinking (L. W. Anderson, Krathwohl, \& Bloom, 2001) and does not necessarily oppose the intended pedagogical design but can be seen as devaluing the power of designing the ability to construct knowledge (Duffy \& Cunningham, 1996; Hull \& Saxon, 2009). As a result, it is not uncommon, especially in the early courses in the program, for students to experience frustration that their ideas of what it means to learn (i.e., passively learning) is being challenged with activities that actively require them to openly participate and activate new mental models of learning (Engeström, 1987; Hull \& Saxon, 2009).

\section{Managing Student Expectations}

As students pursue the program, most are used to pursuing theory-based programs, whereby the knowledge is passed from the instructor to the student. The students are made aware of varying learning theories, models and paradigms (i.e., constructivist, cognitivist, etc.), and trying to move from the paternalistic/passive learning methods towards an active learning method in an online mode necessitates a paradigm shift (Denzau \& North, 1994; Lycke, Grøttum, \& Strøms $\varnothing$, 2006; Ramalingam, LaBelle, $\&$ Wiedenbeck, 2004). A key challenge includes finding a participation framework that values a best practice approach to instructional design, while at the same time, providing the flexibility to acquire contextual (i.e., including cultural) real-world competencies that most students would typically value. The acknowledgement that the instructional design field requires designers to perform based on including review-and-reflecting activity rather than just "knowing" is a key driver for the program (Finlay, 2008; Knowles, 1984; Schön, 1983). Thus, creating a model for 
learning and performing in the field of instructional design in this region requires that the delivery of the program should do the following:

1. Identify the existing knowledge of the [potential] student

2. Present examples of the desired skills (i.e., instructional design capabilities)

3. Design a map to get from the existing knowledge to the desired skills

This means that the existing knowledge and the expected pre-requisite knowledge may not be the same--or even similar. It also means that the examples of the desired skills will not be relatable to the student due to the unawareness of the field. In an effort to understand the field, reviewing past understandings and providing new knowledge requires a strong desire to cognitively change (Festinger, 1962; Harmon-Jones \& Harmon-Jones, 2007). Additionally, because of the delivery mode and the cultural belief systems, building relationships between the instructor and the student is even more challenging. Addressing the varying perceptions of the students with regards to instructor nationality/origin, geographical location, and delivery of instruction to an online Caribbean community has also influenced behaviors in the online delivery environment (Lam, 2015; Rienties \& Rivers, 2014; Shea \& Bidjerano, 2010).

Drawing on perceptions and trying to bridge the gap between culturally specific examples and the field is a daunting task. Using examples from the field which may discuss topics that are considered culturally taboo is $a$ risk-driven task in this online learning environment (Ellison, Steinfield, \& Lampe, 2007). An example of such is the use of Sir Ken Robinson's (2010) Ted Talk on Changing the Education Paradigm. In a discussion about which instructional principles can be used to guide the design in a course, the students can easily venture into a discussion on why children should be allowed to collaborate in the design of their learning environment as well as why Caribbean adult learners expect to be governed by the principles of a foreign theorist. These examples provide support for addressing the need to be educated on the principles of the field, but challenging the value system and finding supports to bolster the effort can be quite difficult task.

\section{Participation Framework to Add Value}

The underlying justification for interaction in the distance learning online setting hinges on the premise that learning is participatory and requires active involvement and collaboration in the learning process (T. Anderson, 2008; Stahl, 2005; Stahl, Koschmann, \& Suthers, 2006). Salmon (2002), Garrison(2007) and others have sought to provide guidance on facilitating and assessing participation in the online environment. The implementation of a framework to facilitate and motivate participation in the online setting remains a challenge. This is due in part to the 
various challenges and disposition of learners. The participation framework used in the program has revealed the utility of adopting various approaches in facilitating and motivating participation principles. The management of student participation in the program has been affected through the design of a number of assessment inputs. These inputs lay a foundation for building critical thinking, knowledge creation, collaborative knowledge building, reflection and deeper understanding (Milheim, 2014; Stahl, 2005). It therefore seems commonplace that the design of online classroom spaces to facilitate effective participation and learning should be an integral part of the design process (Berge, 1995; Davie \& Wells, 1991). In fact, Bullen (2007) contends that student participation is affected by the activities as well as student situational and dispositional factors. Against this background, the design and facilitation for effective participation must therefore consider the students' situational and dispositional contexts in order to provide context for understanding students, their dispositions, and their challenges.

\section{SOLUTIONS: INTERPRETING VALUE TO A STUDENT}

It is believed that using varying modes to guide the learning, as well as modelling the method through which learning can be delivered, is the key. This is specifically important for this field where understanding different theoretical foundations is important (Spector et al., 2006). Teaching students about instructional design whilst using instructional design methods to illustrate the theoretical foundations can be a challenging task; especially for online delivery. This is even more pertinent when the delivery of the foundational knowledge differs from the method the students are used to using to learn, with further complications to the numerous challenges of using an online platform to design an instructional design course (Costa, 2013; Henderson, 2007; Hofstede, 2001). While, the supporting telecommunications infrastructure in each island may individually be sufficient to facilitate any learning design innovations for the course, the access for students to costly Internet Service Providers (ISPs) can create restrictions. This means that learning designs that include video, audio, or simulated interactions can lose their intended meaning and thus create contextual differences and meanings for novice instructional designers. Coupling this challenge with cultural expectations often means that finding a neutral ground for tools, techniques, and technologies can also be difficult.

\section{Designing to Measure Participation}

When thinking of providing a solution for measuring a student's participation in an online environment, the designer must be sure that the solution models the process 
of moving from the subjective value system of learning, which is passive, to a view that encourages unsettling dissonance in the student's ability to learn (Costa, 2013; Festinger, 1962; Henderson, 2007). This process can be illustrated both Bourdieu's (2011) theory of habitus and Elmore's modes of leadership, where, based on Elmore (2016) students are initially described as being hierarchical individuals with the intention of being progressed towards being distributed collective individuals. As the classification of the student is identified using leadership behaviours, understanding how those leadership behaviours are manifested and grown in each individual student is part of the process (Costa, 2013). This framework, while being developed with insight from face-to-face to online settings, provides an interesting point of reflection to advance the participation framework. The framework will take into account the disposition and situational contexts of the students and the learning environment (Costa, 2013; Henderson, 2007). The design and facilitative process needed to guide this perspective requires understanding of what is valued by the student and should easily incorporate with the program's objectives, thus re-creating the student's value system. Once this is re-created, the assessment of the reported participation must include some explicitly stated self-reflection on the participation process.

Elmore's (2016) mode of leadership describes four quadrants which guide student learning behavior. In the first quadrant, as a "Hierarchical Individual," the student in this context will expect similar behaviors that are demonstrated in a didactic and paternalistic environment. Here, if Hofstede's (2001) cultural dimensions are included, students will respond well to large power distance, based on an individualistic foci, with strong uncertainty avoidance. Adding to the cultural dimensions, the individual's behaviour although categorised incorporates their prior experiences and contributes to their decisions going forward (Bourdieu, 2011). In the second quadrant, "Hierarchical Collective," the student in this context will expect similar behaviors that are demonstrated in a didactic and paternalistic environment, but will be guided by the societal-cultural norms. If Hofstede's (2001) cultural dimensions are included, students will still respond well to large power distance, but it will be based on a group/collectivism foci with a strong uncertainty avoidance. In the third quadrant, "Distributed Individual," the student in this context will be open to having and expressing his or her own opinions. When referencing Hofstede's (2001) cultural dimensions, students will respond well to a smaller power distance, based on an individualistic foci, with fluctuations between a weak and strong uncertainty avoidance. In the last quadrant, "Distributed Collective," the student in this context will still be open to having and expressing his or her own opinions. The difference, however, would be when referencing Hofstede's (2001) cultural dimensions. Students will respond well to a smaller power distance, guided by the societal-cultural norms, and focus on a group/collectivism foci with fluctuations between a weak and strong uncertainty avoidance. 
The normalized perspectives drawn from both Elmore's (2016) quadrants, Hofstede's (2001) cultural dimensions and Bourdieu's (2011) considerations of the student as a situated individual are based on the differences in the sampling of the population in the online courses and the instructors' own perceptions when delivering in the program. Students who are from the wealthier CARICOM countries can be seen as less conservative than their other counterparts. This means that providing a generalized approach to the entire online course context can be swayed by the sample - thus confounding the principles and practices of delivering online education in this context. As a new student begins in the program, instructors perceive that the student should begin as a Hierarchical Individual, and as each student moves through the program, it is hoped that they become part of the Distributed Collective. In an effort to model the expected cultural dimensions needed for the field whilst acknowledging the behaviors that are introduced to the environment, the assessment of participation will conceptually vary as the program progresses (see Table 1).

\section{Assessing Participation to Reaffirm Value Proposition}

The traditional assessment framework for CARICOM courses still uses declarative knowledge assessing methods - this includes rote memorization techniques. This means that essays (short and/or long) may be a typical design of an assessment, and as such, are expected by the students in this context. As the participation strategies in this program move from the hierarchical individual to the distributed collective, the assessment criteria will measure higher-level abilities (i.e., application, analytical, etc.). This means that there is the ability to increase the student participation towards the top of Bloom's Taxonomy, thus becoming more reflective and creative (Anderson et al., 2001). Incorporating such into the assessment model for the program will mean less dependency on the traditional and commonly used features/tools used in word-processing software and more creative use of other features in the same tools to create simulations and information visualizations of solutions. Both spectrums of the participation strategy should require some measure of reflection to accommodate the changing perspectives as individual performance and knowledge increases (Knowles, 1984; Rogers, 2003; Schön, 1983). This should also provide a foundation for measuring the ability to respond to the expected need of a professional network of knowledge systems, which is a key requirement for acquiring increased expertise in this profession - instructional design (Lave \& Wenger, 1990; Wenger, 1998). 


\section{Table 1. Conceptual framework for assessing student participation}

\begin{tabular}{|c|c|}
\hline $\begin{array}{l}\text { Hierarchical Individual - The hierarchical } \\
\text { individual likes individual achievement with clear } \\
\text { outcomes and indication for success. } \\
\text { Presentation of content } \\
\text { Content and learning experience requires student to } \\
\text { seek continued and active participation. } \\
\text { Participation Strategies } \\
\text { Instructional designers are required to design } \\
\text { participation that allows learners to begin thinking } \\
\text { about being less passive. This means } \\
\text { Clear instructions on what is required for } \\
\text { individual success in weekly/modular activity. } \\
\text { Structured learning environment with feedback } \\
\text { following weekly/modular activity. } \\
\text { Students will have increased access to } \\
\text { facilitators. } \\
\text { Students will be encouraged to seek out } \\
\text { facilitator for tutorials or tutorials can be pre- } \\
\text { recorded and accessed by student. }\end{array}$ & $\begin{array}{l}\text { Distributed Individual- Students value endless } \\
\text { opportunity to gain depth of understanding using } \\
\text { various means. Success is seen in the way individuals } \\
\text { are able to draw of distributed approaches in } \\
\text { reaching outcomes/success. } \\
\text { Presentation of Content } \\
\text { Provide students with access to multiple channels } \\
\text { - Journal articles, videos, access to e-books, } \\
\text { simulations, etc. } \\
\text { Participation strategies } \\
\text { Instructional designers are required to design } \\
\text { participation that allows students to explore multiple } \\
\text { channels, guidance on judgement and selection of } \\
\text { credible sources needed. This means } \\
\text { Scaffolding participation and slowly removing } \\
\text { some supports so that students can build their own } \\
\text { expertise } \\
\text { resequiring students to openly and actively share } \\
\text { resources and knowledge }\end{array}$ \\
\hline $\begin{array}{l}\text { Hierarchical Collective - Learning in this quadrant } \\
\text { is seen as community function and requires } \\
\text { active participation of student in networking and } \\
\text { would thrive in online group discussions, group } \\
\text { presentations. Success for individual emanates from } \\
\text { shared group goals and achievement. } \\
\text { Presentation of content } \\
\text { Students should be presented with multiple points of } \\
\text { interaction } \\
\text { Participation Strategies } \\
\text { Instructional designers are required to design } \\
\text { participation that allows learners to think about } \\
\text { the success of the group and how it benefits them } \\
\text { individually. This means } \\
\text { group and shared activity. } \\
\text { Group members provide feedback and are } \\
\text { encouraged to peer-assess and support each other } \\
\text { towards success }\end{array}$ & $\begin{array}{l}\text { Distributed Collective - Students in this setting } \\
\text { value external course and module resources while } \\
\text { adhering to learning community expectations. } \\
\text { Student support shared values of community and } \\
\text { contributes to the community of learners. } \\
\text { Presentation of context } \\
\text { Learning and presentation of context is complex and } \\
\text { networked. Students should be given option/access to } \\
\text { additional means to share additional course content - } \\
\text { A twitter feed. } \\
\text { Participation strategies } \\
\text { Instructional designers are required to design } \\
\text { participation that allows students to explore use of } \\
\text { external networks. This means } \\
\text { The use of online social networks as supporting } \\
\text { resources such as LinkedIn and Twitter can provide } \\
\text { some of this need. } \\
\text { - Students value network learning }\end{array}$ \\
\hline
\end{tabular}

\section{FUTURE RESEARCH DIRECTIONS}

The discussion in this chapter, is strongly governed by its context and the individuals situated within the context - the topic being instructed, the method of delivery, and the historical nature of the students in the region. This can provide some guidance to others as the conceptual framework is still in draft form. Expanding the conceptual framework to include more of Hofstede's cultural dimensions and then testing the combined framework against the program objectives is key. This then begs the question as to 
- What online teaching strategies should be used to deliver subjects that require specialized skills taking note of the contextual environment?

- Is it sufficient to ignore the factors that influence improved student participation?

- What accommodations should be made in an instructional design online curriculum where there are skills that are required of the student to perform as an individual but also in group-based activities?

- How can the design of online programs achieve their program objectives, at a distance and in timelines guided by semester systems?

These questions may not be unique, but they do create more paths for creative solutions.

\section{CONCLUSION}

This chapter discussed the design used to create a learner value system in a diverse online program in the Caribbean. The value system proposed is knowledge based and is governed by cultural, individual uniqueness and subject specificity. Delivering an online program for a diverse population is not unusual. The delivery becomes complex when the subject requires behaviors which differ culturally from the population. Managing the student cultural expectations, combined with a drive for change, will create a complex yet unique solution. Teaching instructional design online fits this need where the complexity of the field, coupled with the diverse characteristics of students and their environment, can challenge the core principles of the field. Building on the characterization of the students to create a framework of delivery, thus adding value to the program, for these students is key.

\section{REFERENCES}

Anderson, L. W., Krathwohl, D. R., \& Bloom, B. S. (2001). A taxonomy for learning, teaching, and assessing: A revision of Bloom's taxonomy of educational objectives. Allyn \& Bacon.

Anderson, T. (2008). Towards a theory of online learning. In Theory and Practice of Online Learning (pp. 45-74).

Beckles, H. (1993). Caribbean slave society and economy: a student reader. New Press. 
Beckman, K., Bennett, S., \& Lockyer, L. (2014). Understanding students use and value of technology for learning. Learning, Media and Technology, 39(3), 346-367. doi:10.1080/17439884.2013.878353

Berge, Z. L. (1995). Facilitating computer conferencing: Recommendations from the field. Educational Technology, 35, 22.

Bourdieu, P. (2011). The forms of capital. (1986). Cultural Theory: An Anthology, 1, 81-93.

Bullen, M. (2007). Participation and critical thinking in online university distance education. International Journal of E-Learning \& Distance Education, 13(2), 1-32.

Carrington, E. W. (1993). The Future of Education in the Caribbean: Report of the CARICOM Advisory Task Force on Education. Eric Database.

Clark, R. (1983). Reconsidering research on learning from media. Review of Educational Research, 53(4), 445-459. doi:10.3102/00346543053004445

Collins, M. (2000). Comparing web, correspondence and lecture versions of a second-year non-major biology course. British Journal of Educational Technology, 31(1), 21-27. doi:10.1111/1467-8535.00132

Costa, C. (2013). The habitus of digital scholars. Research in Learning Technology, 21(1), 21274. doi:10.3402/rlt.v21.21274

Czerniewicz, L., \& Brown, C. (2013). The habitus of digital strangers in higher education. British Journal of Educational Technology, 44(1), 44-53. doi:10.1111/ j.1467-8535.2012.01281.x

Czerniewicz, L., \& Brown, C. (2014). The habitus and technological practices of rural students: A case study. South African Journal of Education, 34(1), 1-14. doi:10.15700/201412120933

Davie, L. E., \& Wells, R. (1991). Empowering the learner through computermediated communication. American Journal of Distance Education, 5(1), 15-23. doi:10.1080/08923649109526728

Denzau, A. T., \& North, D. C. (1994). Shared mental models: Ideologies and institutions. Kyklos, 47(1), 3-31. doi:10.1111/j.1467-6435.1994.tb02246.X 
Dickson-Deane, C., \& Deane, W. A. (2013). Implementing Infrastructure-Related Education Technology Solutions at the Government Primary and Secondary School Level. In Cases on Educational Technology Planning, Design, and Implementation: A Project Management Perspective. Hershey, PA: IGI Global. doi:10.4018/978-14666-4237-9.ch018

Duffy, T., \& Cunningham, D. (1996). Constructivism: Implications for the design and delivery of instruction. In Handbook of Research for Educational Communications and Technology (pp. 170-198).

Ellison, N. B., Steinfield, C., \& Lampe, C. (2007). The Benefits of Facebook Friends: Social Capital and College Students Use of Online Social Network Sites. Journal of Computer-Mediated Communication, 12(4), 1143-1168. doi:10.1111/j.10836101.2007.00367.x

Elmore, R. F. (2016). Modes of leadership. Retrieved from https://courses.edx.org/ c4x/HarvardX/GSE2x/asset/modes-of-leadership.pdf

Engeström, Y. (1987). Learning by expanding: an activity-theoretical approach to developmental research. Helsinki, Finland: Orienta-Konsultit, OY.

Festinger, L. (1962). A theory of cognitive dissonance (Vol. 2). Stanford university press.

Finlay, L. (2008). Reflecting on 'Reflective practice. Practice-Based Professional Learning Centre.

Garrison, D. R. (2007). Online Community of Inquiry Review: Social, Cognitive, and Teaching Presence Issues. Journal of Asynchronous Learning Networks, 11(1), $61-72$.

Harmon-Jones, E., \& Harmon-Jones, C. (2007). Cognitive dissonance theory after 50 years of development. Zeitschrift für Sozialpsychologie, 38(1), 7-16. doi:10.1024/0044-3514.38.1.7

Harvard, X. (2017, May 1). Leaders of Learning [Course]. Retrieved July 7, 2017, from https://www.edx.org/course/leaders-learning-harvardx-gse2x-1

Henderson, L. (2007). Theorizing a multiple cultures instructional design model for e-learning and e-teaching. In Globalized E-Learning Cultural Challenges (pp. 130-153).

Hofstede, G. (2001). Culture's consequences: comparing, values, behaviors, institutions, and organizations across nations (2nd ed.). Thousand Oaks, CA: Sage Publications. 
Hull, D. M., \& Saxon, T. F. (2009). Negotiation of meaning and co-construction of knowledge: An experimental analysis of asynchronous online instruction. Computers \& Education, 52(3), 624-639. doi:10.1016/j.compedu.2008.11.005

Kidd, T. T. (2009). A brief history of eLearning. Online Education and Adult Learning: New Frontiers for Teaching Practices, 46.

Knight, F. W. (1990). The Caribbean: The genesis of a fragmented nationalism (2nd ed.). USA: Oxford University Press.

Knowles, M. (1984). The adult learner: A neglected species (3rd ed.). Houston, TX: Gulf Publishing.

Lam, J. Y. (2015). Autonomy presence in the extended community of inquiry. International Journal of Continuing Education and Lifelong Learning, 8(1), 39.

Lave, J., \& Wenger, E. (1990). Situated Learning: legitimate peripheral participation. Cambridge, MA: Cambridge University Press.

Lycke, K. H., Grøttum, P., \& Strømsø, H. I. (2006). Student learning strategies, mental models and learning outcomes in problem-based and traditional curricula in medicine. Medical Teacher, 28(8), 717-722. doi:10.1080/01421590601105645 PMID: 17594584

Milheim, K. L. (2014). Facilitation across cultures in the online classroom. International Journal of Learning, Teaching and Educational Research, 5(1).

Moore, J. L., Dickson-Deane, C., \& Liu, M. (2014). Designing CMS courses from a pedagogical usability perspective. In Perspectives in Instructional Technology and Distance Education: Research on Course Management Systems in Higher Education (pp. 143-169). Information Age Publishing.

Moore, M. G., \& Kearsley, G. (2011). Distance education: A systems view of online learning. Wadsworth Publishing Company.

Noble, D. F. (1998). Digital diploma mills: The automation of higher education. Science as Culture, 7(3), 355-368. doi:10.1080/09505439809526510

Parrish, P., \& Linder-VanBerschot, J. (2010). Cultural dimensions of learning: Addressing the challenges of multicultural instruction. The International Review of Research in Open and Distributed Learning, 11(2), 1-19. doi:10.19173/irrodl. v11i2.809 
Ramalingam, V., LaBelle, D., \& Wiedenbeck, S. (2004). Self-efficacy and mental models in learning to program. In ACM SIGCSE Bulletin (Vol. 36, pp. 171-175). ACM. Retrieved from doi:10.1145/1007996.1008042

Reiser, D. R. A. (2001). A History of Instructional Design and Technology: Part II: A History of Instructional Design. Educational Technology Research and Development, 49(2), 57-67. doi:10.1007/BF02504928

Rienties, B., \& Rivers, B. A. (2014). Measuring and understanding learner emotions: Evidence and prospects. Learning Analytics Review, 1, 1-28.

Robinson, B., \& Latchem, C. R. (2002). Teacher education through open and distance learning (Vol. 3). New York, London: Routledge Falmer.

Robinson, K. (2010). Changing education paradigms. Retrieved from https://www. ted.com/talks/ken_robinson_changing_education_paradigms

Rogers, E. (2003). Diffusion of innovations (5th ed.). New York: The Free Press.

Rubin, V. (1960). Caribbean studies (A Symposium). Retrieved from http://cat.inist. $\mathrm{fr} /$ ?aModele $=$ afficheN\&cpsidt $=15819760$

Rubin, V. D. (1957). Caribbean studies: a symposium (Vol. 1956). Institute of Social and Economic Research, University College of the West Indies.

Salmon, G. (2002). E-tivities: The key to active online learning. Psychology Press.

Schön, D. (1983). The reflective practitioner. New York: Basic Book.

Shea, P., \& Bidjerano, T. (2010). Learning presence: Towards a theory of selfefficacy, self-regulation, and the development of a communities of inquiry in online and blended learning environments. Computers \& Education, 55(4), 1721-1731. doi:10.1016/j.compedu.2010.07.017

Spector, J. M., Klein, J. D., Reiser, R. A., Sims, R., Grabowski, B. L., \& de la Teja, I. (2006). Competencies and Standards for Instructional Design and Educational Technology.IBSTPI-ITFORUM. Retrieved from http://itforum.coe.uga.edu/paper89/ ITForumpaper89.pdf

Squires, D., \& Preece, J. (1996). Usability and learning: Evaluating the potential of educational software. Computers \& Education, 27(1), 15-22. doi:10.1016/03601315(96)00010-3

Stahl, G. (2005). Group cognition in computer-assisted collaborative learning. Journal of ComputerAssisted Learning, 21(2),79-90.doi:10.1111/j.1365-2729.2005.00115.x 
Stahl, G., Koschmann, T., \& Suthers, D. (2006). Computer-supported collaborative learning: An historical perspective. In Cambridge Handbook of the Learning Sciences. Retrieved from http://gerrystahl.net/cscl/CSCL_English.htm

Thomas, M., Mitchell, M., \& Joseph, R. (2002). A cultural embrace. TechTrends, 46(2), 40-45. doi:10.1007/BF02772075

Wenger, E. (1998). Communities of practice: learning, meaning, and identity. New York: Cambridge University. doi:10.1017/CBO9780511803932 